\title{
A utilização de novas tecnologias no âmbito da investigação criminal e as suas limitações legais: a interceptação de comunicações em massa e os softwares de espionagem
}

The use of new technologies in criminal investigations and their legal limitations: interception of mass communications and espionage software

\section{EDUARDO BOLSONI RIBOLI'}

GALILEU - REVISTA DE DIREITO E ECONOMIA · e-ISSN 2184-1845

Volume XIX $\cdot 1^{\text {st }}$ July Julho - 31 $1^{\text {TH }}$ December Dezembro $2018 \cdot$ pp. 49-77

DOI: https://doi.org/10.26619/2184-1845.XIX.2.3

Submited on Submitted on October $04^{\text {th }}, 2018$. Accepted on November $11^{\text {th }}, 2018$

Submetido em 4 de Outubro, 2018 - Aceite a 11 de Novembro, 2018

RESUMO O presente estudo tem como finalidade analisar a problemática relacionada à utilização de novas tecnologias no âmbito da investigação criminal, em particular novos métodos ocultos de investigação como a interceptação de comunicações em massa e os softwares de espionagem, e os requisitos necessários para conferir legitimidade à aplicação destes novos recursos, de modo a impedir arbitrariedades das autoridades responsáveis pela investigação e garantir a proteção dos direitos fundamentais e das liberdades individuais do indivíduo investigado.

PALAVRas-chaVE interceptação de comunicações, método oculto de investigação, meio oculto de obtenção de prova, software de espionagem, malware.

ABSTRACT This paper aims to examine the problems related to the use of new technologies in criminal investigations, in particular new hidden investigation methods such as the interception of mass communications and spying software. It analyses the necessary requirements to confer legitimacy to the use of these new resources in order to prevent the arbitrariness of the investigating authorities and to ensure the protection of the fundamental rights and individual freedoms of the investigated individual.

1 Doutorando em Direito (Especialidade de Ciências Jurídico-Criminais) pela Universidade de Lisboa. Mestre em Ciências Jurídico-Criminais pela Universidade de Coimbra. Membro, bolseiro do FCT, do Ratio Legis - Centro de Investigação e Desenvolvimento em Ciências Jurídicas, da Universidade Autónoma de Lisboa. 
A utilização de novas tecnologias no âmbito da investigação criminal e as suas limitações legais...

EDUARDO BOLSONI RIBOLI

KEYWORDS communications interception, hidden method of investigation, hidden means of obtaining evidence, spying software, malware

\section{Introdução}

Detentores de um indiscutível valor social, os avanços tecnológicos ampliaram e agilizaram os canais de comunicação, revolucionando, assim, a circulação de pessoas, de bens e de informação. Vivemos hoje na designada "sociedade da informação"2, cujas características definidoras consistem no fluxo constante de informação e conhecimento como recursos fundamentais e que desempenham papéis centrais na orientação do comportamento social, em especial mediante o uso de sistemas informáticos e de ferramentas como a Internet, Facebook, Wikipedia, LinkedIn, Twitter etc.

A evolução e a proliferação dos canais de comunicação, dos sistemas informáticos e dos dispositivos eletrônicos, aliadas à rapidez e à facilitação do anonimato em ambiente digital, acabaram também por estimular o desenvolvimento de novas atividades criminais. Com efeito, não só a sociedade em geral foi paulatinamente se mundializando e moldando pela rápida troca de fluxos de informação, como também a criminalidade se adaptou às novas condições, adotando formas mais organizadas, internacionalizadas e informatizadas. Novas práticas delitivas foram originadas - especialmente aquelas ocorridas em ambiente digital, os chamados cibercrimes -, acompanhadas por novos meios para a consumação de ilícitos penais tradicionais, os quais, em muitos casos, tiveram sua prática facilitada (v.g. crimes de terrorismo, crime de pornografia de menores e delitos de tráfico de estupefacientes e de pessoas). Esta mencionada facilidade para a prática de ilícitos penais em ambiente digital contrasta com a dificuldade acrescida com que se deparam os órgãos de perseguição penal na identificação do fato criminoso e dos agentes envolvidos, na realização de investigações em escala global e no combate a estas práticas ilícitas. Neste cenário global digital, não restam dúvidas de que a ameaça do terrorismo e de crimes graves (mormente o tráfico de estupefacientes, o tráfico de seres humanos e a exploração e tráfico de menores) são perigos reais e imprevisíveis em qualquer Estado.

Tamanha (r)evolução apresenta incontáveis novos desafios para os órgãos policiais, para as autoridades judiciais e para o sistema jurídico de cada país, especialmente no

2 Cf. VERVAELE, J. A. E, - Surveillance and Criminal Investigation: Blurring of Thresholds and Boundaries in the Criminal Justice System? In: Reloading Data Protection: Multidisciplinary Insights and Contemporary Challenges. Dordrecht, Heidelberg, London, New York: Springer, 2014, pp. 118-119. 
campo da recolha da prova penal. A ameaça do terrorismo, a proliferação de medidas antiforenses $^{3}$ (como a criptografia ${ }^{4}$ ) e a própria infraestrutura das (novas) tecnologias de comunicação $0^{5}$ desafiam o modo como as autoridades policiais e judiciais operam em matéria de investigação criminal. Na verdade, os novos obstáculos apresentados à investigação pela criminalidade tecnologicamente engajada decorrem mais das tecnologias utilizadas pelos criminosos do que das novas práticas ilícitas - exclusiva ou maioritariamente em ambiente digital - criadas. São os novos dispositivos eletrônicos e sistemas informáticos assimilados pela criminalidade que obstaculizam a persecução penal, mas que também podem a facilitar.

Os métodos tradicionais de obtenção de prova mostram-se cada vez mais inadequados ${ }^{6}$ para contornar os óbices decorrentes da evolução tecnológica. A criptografia, a ocultação de dados, a destruição de informações, as diferentes rotas de comunicação na Internet etc. atualmente demandam uma atuação muito mais incisiva dos órgãos responsáveis pela investigação criminal - guardada a gravidade do ilícito, evidentemente, em respeito aos princípios a serem observados em matéria de métodos ocultos de obtenção de prova7 -, exigindo também a assimilação e aperfeiçoamento de tecnologias investigativas pelo Estado no exercício do seu poder punitivo. Já não basta unicamente interceptar uma comunicação, o seu conteúdo pode estar encriptado. Já não basta apreender um computador, o seu con-

3 Técnicas e/ou programas informáticos que ocultam a identidade de um indivíduo e a informação por ele transmitida ou a ele enviada via telecomunicação, bem como os dados armazenados em um sistema informático ou dispositivo eletrônico (CONLAN, Kevin; BAGGILI, Ibrahim; BREITINGER, Frank - Anti-forensics: Furthering digital forensic science through a new extended, granular taxonomy. In Digital Investigation. Amsterdam, New York. ISSN 1742-2876. v. 18 (Supplement), 2016, p. 566).

É importante destacar que a utilização de medidas antiforenses não implica necessariamente a predisposição à prática de crimes, elas podem ser empregadas simplesmente para assegurar a privacidade do indivíduo, e de terceiros, para fins lícitos. As medidas antiforenses servem, por vezes, até mesmo como uma ferramenta de segurança contra crimes que ocorrem por meio de sistemas informáticos, protegendo o usuário comum da criminalidade em ambiente digital.

4 Técnica que transforma um texto simples em um formato obscuro, codificado, através da utilização de um algoritmo matemático, tornando a informação ilegível a terceiros (esta somente pode ser acessada, tornando-se legivel, ou descriptografada, pelo destinatário da informação) (GERCKE, Marco - Understanding Cybercrime: A Guide for Developing Countries. Geneva: International Telecommunication Union, 2011, p. 146).

5 Uso de computação em nuvem, sistemas de comunicação via fibra óptica e a conexão à Internet através de uma rede sem fios são exemplos de tecnologias que impõem óbices à atividade investigativa (POOL, R. L. D.; CUSTERS, B. H. M - The Police Hack Back: Legitimacy, Necessity and Privacy Implications of The Next Step in Fighting Cybercrime. In European Journal of Crime, Criminal Law and Criminal Justice. Deventer. ISSN 0928-9569. V. 25, N. ${ }^{\circ}$ 2, 2017, p. 130).

6 Como a obtenção de informações em ambiente digital, um espaço que desafia métodos tradicionais de colheita de prova por não alcançarem os dados contidos em sistemas informáticos e aparelhos eletrônicos. Essa foi uma das razões que levaram o legislador português a editar a Lei n. ${ }^{\circ}$ 109/2009, de 15 de Setembro (autointitulada "Lei do Cibercrime"), a qual incluiu no ordenamento jurídico português novos meios de obtenção de prova na tentativa de superar os desafios impostos no ambiente digital.

7 Catálogo de crimes, indícios de suspeita, subsidiariedade, proporcionalidade, requerimento do órgão acusador e autorização judicial, posterior notificação ao investigado, por exemplo. 
teúdo pode ter sido encriptado ou eliminado automaticamente. Já não basta ativar o GPS de um smartphone para determinar a sua localização, as coordenadas podem ser fictícias.

Destarte, os Estados necessitam de ponderar sobre a eficácia dos meios de obtenção de prova à disposição em seu ordenamento jurídico e de idealizarem novas formas de obtenção de prova capazes de ultrapassar os desafios erigidos pelas evoluções decorrentes da sociedade mundializada da informação, de modo a cumprir o seu dever de zelo pela segurança dos seus cidadãos, e, ao mesmo tempo, o dever de zelo pelos direitos e garantias fundamentais dos indivíduos investigados.

A necessidade de superação das inadequações reveladas pelos métodos de obtenção de prova convencionais faz surgir novos instrumentos de investigação criminal, capazes de alcançar de modo rápido e eficaz informações em patamares - tanto em abrangência quanto em intromissão à direitos e garantias fundamentais - nunca antes vistos, porém a grandes custos, como ocorre nos casos que serão analisados no presente estudo.

\section{Dos métodos ocultos de investigação criminal}

É a partir deste cenário de evolução tecnológica, de assimilação de novas tecnologias por criminosos e de necessidade de criação de ferramentas eficazes para fins investigativos que ganham relevo os chamados métodos ocultos de investigação - métodos de obtenção de prova efetuados sem o conhecimento do indivíduo investigado ${ }^{8}-$, devido à sua capacidade de obtenção de informações dificilmente alcançáveis pelos métodos tradicionais e, dependendo da tecnologia empregada, de colheita de dados previamente a tentativas de sua ocultação ou destruição. Proliferam nesse contexto o uso de interceptações de comunicações (escutas telefônicas, intromissão no correio eletrônico, escutas online, por exemplo), recurso a agentes encobertos, videovigilância, gravações ambiente e localização por GPS.

Diante da evidente possibilidade de restrição de diferentes direitos fundamentais (intimidade da vida privada, inviolabilidade de domicílio, das telecomunicações ou da correspondência, entre outros), os métodos ocultos de investigação são reconhecidos por sua excepcionalidade. Com efeito, tratam-se de medidas que dependem de previsão legal;

8 "[O]s métodos ocultos de investigação representam uma intromissão nos processos de acção, interacção e comunicação das pessoas concretamente visadas, sem que estas tenham conhecimento do facto nem dele se apercebam. Que, por causa disso, continuam a agir, interagir, a expressar-se e a comunicar de forma 'inocente', fazendo ou dizendo coisas de sentido claramente auto-incriminatório ou incriminatório daqueles que com elas interagem ou comunicam. De forma simplificada e reducionista, os meios ocultos de investigação levam as pessoas atingidas - normalmente o suspeito - a 'ditar' inconscientemente para o processo 'confissões' não esclarecidas nem livres" (ANDRADE, Manuel da Costa - "Bruscamente no Verão passado", a reforma do código de processo penal: observações críticas sobre uma lei que podia e devia ter sido diferente. Coimbra: Coimbra Editora, 2009, pp. 105-106). 
da demonstração da necessidade de sua aplicação (dificuldade de obtenção da prova e/ou esgotamento de outras medidas); e de um juízo de proporcionalidade entre os interesses da Justiça e a restrição de direitos individuais ${ }^{9}$. Em Portugal - por força da interpretação conjunta dos artigos $18 .^{\circ}$, n..$^{o s} 3$ e 2, e $32 .^{\circ}$, n..$^{\circ} 8$, todos da Constituição da República Portuguesa, e dos artigos $125^{\circ}, 126 .^{\circ}$, n. $^{\circ} 3$, ambos do Código de Processo Penal - os métodos ocultos de investigação são reconhecidos como "métodos relativamente proibidos"10 de prova, os quais reclamam uma robusta, clara e densa previsão legal. A sua regulamentação não deve se ater unicamente à observância aos princípios e às disposições da ordem jurídica nacional e supranacional, os métodos relativamente proibidos de prova requerem previsão legal densa suficiente para que haja a menor restrição possível a direitos fundamentais, tão mais densa quanto mais intrusiva a direitos individuais for a medida, principalmente quando se tratar de um método oculto de investigação.

Destarte, a assimilação de novas tecnologias para fins investigativos somente encontrará legitimidade mediante uma regulamentação dotada de qualidade. Essa é uma das problemáticas centrais em tema de métodos ocultos de investigação, questão que analisaremos a seguir ao estudarmos a interceptação de comunicações em massa, a partir do entendimento do Tribunal Europeu dos Direitos do Homem, e o uso de software de espionagem para fins investigativos.

\section{A interceptação de comunicações em massa e o caso BIG Brother WATCH AND OTHERS V. THE UNITED KINGDOM}

No dia 13 de setembro de 2018, o Tribunal Europeu dos Direitos do Homem julgou o caso Big BRother Watch AND OTHERS V. THE United Kingdom, no qual enfrentou o tema da conformidade do ordenamento jurídico do Reino Unido com a Convenção Europeia dos Direitos do Homem, em específico o programa de interceptação em massa do Reino Unido; a regulamentação sobre a partilha entre países e territórios estrangeiros de dados obtidos por agências de inteligência; e a regulamentação sobre a obtenção de dados de comunicações de provedores de serviços de comunicação.

9 MENDES, Paulo de Sousa - Lições de Direito Processual Penal. Coimbra: Almedina, 2015, p. 188 e ss.; ANDRADE, Manuel da Costa - "Bruscamente no... cit., p. 105 e ss; ANDRADE, Manuel da Costa - Sobre as proibições de prova em processo penal. 1. ${ }^{\mathrm{a}}$ ed. (reimpr.). Coimbra: Coimbra Editora, 2013, pp. 117-132, 209 e ss.; RODRIGUES, Benjamim Silva - Da Prova Penal - Tomo II - Bruscamente... A(s) face(s) oculta(s) dos métodos ocultos de investigação criminal. Cascais: Rei dos Livros, 2010, passim; VALENTE, Manuel Monteiro Guedes - Processo penal - Tomo I. 3. ${ }^{\text {a }}$ ed., ver., actual. e aument. Coimbra: Edições Almedina, 2010, p. 448 e ss.

10 MENDES, Paulo de Sousa - Lições de Direito... cit., p. 180. 
Trata-se de uma decisão paradigmática em matéria de investigação criminal, com o potencial de impactar de maneira significativa programas de vigilância de diferentes países, em especial Estados europeus, bem como os seus ordenamentos jurídicos no que diz respeito ao regime de interceptação de comunicações.

O caso Big Brother Watch and Others V. The United Kingdom diz respeito ao julgamento, em conjunto, de três queixas interpostas contra o REINO UNIDo pelos requerentes BIG BROTHER WATCH (organização britânica, apartidária e sem fins lucrativos, de proteção às liberdades civis e à privacidade), ENGLISH PEN (entidade filantrópica que promove a liberdade de expressão), OPEN Rights GROUP (organização britânica de proteção e preservação dos direitos e liberdades digitais) e CONSTANZE KuRz (especialista em vigilância digital e porta-voz do grupo alemão "Computer Chaos Club", o qual realiza campanhas para ressaltar fragilidades em redes e programas informáticos que coloquem em risco interesses públicos, como o direito à privacidade) (queixa n..$^{\circ}$ 58170/13); BUREAU OF INVEsTIGATIVE JOURNALISM (organização sem fins lucrativos criada por jornalistas do Reino Unido) e Alice Ross (jornalista, integrante do Bureau of Investigative Journalism) (queixa n. ${ }^{\circ}$ 62322/14); Amnesty International Limited, Bytes for All, The National CounCIL FOR CIVIL LIBERTIES, UMA ENTIDADE PRIVADA COM FOCO NO DIREITO À PRIVACIDADE A Nível INTERNACiONAL COM SEDE EM LoNdRes (NÃo NOMEADA), THE AMERICAN CIVIL Liberties Union, The Canadian Civil Liberties Association, The Egyptian Initiative for Personal Rights, Társaság a Szabadságjogokért, An Chomhairle um Chearta Daonna e The Legal Resources Centre (todas entidades ou organizações de direitos humanos e/ou de direito(s) à privacidade) (queixa n..$^{\circ}$ n. ${ }^{\circ} 24960 / 15$ ).

As queixas foram propostas logo após as revelações efetuadas por Edward Snowden, que em 2013 e nos anos seguintes divulgou documentos e informações confidenciais sobre os programas de vigilância eletrônica globais operados pelos serviços de inteligência dos Estados Unidos da América e do Reino Unido. Os requerentes alegaram acreditar que, em razão da natureza das atividades por eles exercidas (relacionadas ao jornalismo, à defesa do direito de liberdade de expressão e à defesa dos direitos humanos), haviam sido alvo de interceptação de comunicações pelos serviços de inteligência governo do Reino Unido, através (1) da interceptação direta pelos programas e sistemas de vigilância eletrônica do governo; (2) da obtenção, pelo governo do Reino Unido, de dados angariados pelo serviço de inteligência de governos estrangeiros, como os Estados Unidos; e (3) da obtenção, pelas autoridades do Reino Unido, de dados concedidos por serviços de comunicação.

Os requerentes questionaram a legalidade das diferentes estratégias dos serviços de inteligência do Reino Unido para interceptar e obter informações em massa e de modo oculto sobre os seus cidadãos e sobre estrangeiros mediante diferentes canais de comuni- 
cação, principalmente através do monitoramento do tráfego da Internet. Uma das estratégias empregadas pelo Government Communications Headquarters (GCHQ) do Reino Unido é a utilização do programa informático TEMPORA, que, entre outras funções, permite a interceptação em massa e gravação tradicional de comunicações telefônicas e a interceptação, coleta e análise do imenso volume de tráfego de dados que circulam pelos conglomerados de cabos de fibra óptica transoceânicos e continentais que estruturam a Internet e a criação de um índice, ou banco de dados, das informações obtidas.

\section{A. Alegações das partes}

\section{a) Requerentes}

No que tange à discussão aqui proposta, os requerentes alegaram violação ao artigo $8 .^{\circ} \mathrm{da}$ Convenção Europeia dos Direitos do Homem ${ }^{11}$ - o qual versa sobre o direito ao respeito pela vida privada e familiar - pela lei britânica que regulava os poderes e medidas de interceptação à época (Regulation of Investigatory Powers Act 2000 - RIPA, atualmente revogada pelo Investigatory Powers Act 2016). Foi questionada a compatibilidade entre a Convenção e o regime de interceptação em massa de comunicações, previsto na seção 8(4) da Regulation of Investigatory Powers ${ }^{12}$.

11 Artigo 8. - Direito ao respeito pela vida privada e familiar "1. Qualquer pessoa tem direito ao respeito da sua vida privada e familiar, do seu domicílio e da sua correspondência". "2. Não pode haver ingerência da autoridade pública no exercício deste direito senão quando esta ingerência estiver prevista na lei e constituir uma providência que, numa sociedade democrática, seja necessária para a segurança nacional, para a segurança pública, para o bem-estar económico do país, a defesa da ordem e a prevenção das infracções penais, a protecção da saúde ou da moral, ou a protecção dos direitos e das liberdades de terceiros".

12 Section 8: "Contents of warrants. (1) An interception warrant must name or describe either- (a) one person as the interception subject; or (b) a single set of premises as the premises in relation to which the interception to which the warrant relates is to take place. (2) The provisions of an interception warrant describing communications the interception of which is authorised or required by the warrant must comprise one or more schedules setting out the addresses, numbers, apparatus or other factors, or combination of factors, that are to be used for identifying the communications that may be or are to be intercepted. (3) Any factor or combination of factors set out in accordance with subsection (2) must be one that identifies communications which are likely to be or to include- (a) communications from, or intended for, the person named or described in the warrant in accordance with subsection (1); or (b) communications originating on, or intended for transmission to, the premises so named or described. (4) Subsections (1) and (2) shall not apply to an interception warrant if- (a) the description of communications to which the warrant relates confines the conduct authorised or required by the warrant to conduct falling within subsection (5); and (b) at the time of the issue of the warrant, a certificate applicable to the warrant has been issued by the Secretary of State certifying- (i) the descriptions of intercepted material the examination of which he considers necessary; and (ii) that he considers the examination of material of those descriptions necessary as mentioned in section 5(3)(a), (b) or (c). (5) Conduct falls within this subsection if it consists in- (a)the interception of external communications in the course of their transmission by means of a telecommunication system; and (b)any conduct authorised in relation to any such interception by section $5(6)$. (6) A certificate for the purposes of subsection (4) shall not be issued except under the hand of the Secretary of State". 
Os requerentes reconheceram que a interceptação em massa possui previsão legal no direito interno britânico, porém questionaram a qualidade da lei, defendendo que a sua complexidade a tornava inacessível ao público, com disposições "abaixo da linha d’água" (below the waterline) e carente de diretrizes legais claras e garantias suficientes contra abusos. Em específico, foi alegado que a seção 8(4) da Regulation of Investigatory Powers Act não observava os seis requisitos identificados pelo Tribunal Europeu dos Direitos do Homem no julgamento do caso WeBER AND SARAVIA V. GERMANY (n. ${ }^{\circ}$ 54934/0o) - no qual fora questionada a compatibilidade do sistema alemão de interceptação de comunicações telefônicas com a Convenção Europeia dos Direitos do Homem, em razão de uma alteração legislativa na Alemanha que ampliou os poderes de interceptação de comunicações do serviço de inteligência alemão ${ }^{13}$-, a saber: (1) os casos de admissibilidade da interceptação de comunicações, em especial a natureza dos crimes que admitem este método de investigação; (2) a definição da categoria de pessoas que podem ter suas comunicações interceptadas; (3) o limite de duração da medida; (4) os procedimentos a serem observados no momento da análise, uso e preservação dos dados obtidos; (5) as precauções a serem tomadas na partilha dos dados com outras partes; e (6) as circunstâncias em que pode ou deve ser realizada a eliminação das gravações e/ou a destruição dos suportes físicos em que os dados foram guardados.

Em suma, os requerentes alegaram que (1) os crimes que permitiam o recurso à interceptação de comunicações não estavam suficientemente delimitados na lei em razão da evasividade do texto legal, característica que poderia abrir margem a arbitrariedades; (2) qualquer pessoa estava potencialmente sujeita a ter suas comunicações interceptadas, diante da indefinição legal quanto à distinção entre comunicações internas e externas e o seu âmbito de aplicação; (3) havia indefinição dos limites temporais da vigilância, a qual poderia perdurar ad infinitum; (4) os procedimentos de análise, seleção e preservação do material interceptado eram carentes de garantias adequadas; (5) em relação à comunicação de material interceptado, a garantia de que a divulgação se limitasse ao "mínimo necessário

13 Em suma, no caso Weber and Saravia $v$. Germany os requerentes alegaram violação da lei alemã sobre a limitação da privacidade das comunicações postais e telecomunicações (Gesetz zur Beschränkung des Brief-, Post- und Fernmeldegeheimnisses) aos artigos $8 .^{\circ}, 10^{\circ}$ e $13 .^{\circ}$ da Convenção Europeia dos Direitos do Homem, em virtude de uma alteração na referida norma, ocorrida em 1994, que ampliou os poderes de interceptação de comunicações do sistema de inteligência alemão ao criar a possibilidade de "monitoramento estratégico de telecomunicações", o qual consiste na coleta de informação através da interceptação de comunicações a fim de identificar e evitar graves ameaças à República Federal da Alemanha (como um ataque armado em seu território ou prática de crimes graves como delitos relacionados ao terrorismo). Os requerentes, uma jornalista alemã (Weber) e um cidadão uruguaio (Saravia), alegaram que a legislação alemã e a técnica investigativa de monitoramento estratégico de telecomunicações violavam seus direitos ao respeito pela vida privada e correspondência. O Tribunal Europeu dos Direitos do Homem não reconheceu nenhuma das violações alegadas e considerou que a legislação alemã era devidamente densificada e continha salvaguardas suficientes para proteger os direitos fundamentais dos investigados, uma legislação dotada do que o Tribunal classifica como quality of law. 
A utilização de novas tecnologias no âmbito da investigação criminal e as suas limitações legais...

EDUARDO BOLSONI RIBOLI

para os fins autorizados"14 era ineficaz; (6) inexistiam salvaguardas eficazes ou vinculativas referentes à detenção desproporcionada dos dados interceptados.

Foi também alegado pelos requerentes que os requisitos identificados no caso WEBER já estavam defasados no contexto atual, em virtude de o referido caso ter sido julgado em 2006 , sendo que o desenvolvimento tecnológico posterior poderia significar a possibilidade de o Governo criar perfis detalhados e intrusivos de aspectos íntimos de vidas privadas a partir da análise de padrões de comunicação em uma interceptação em massa. Por conseguinte, os requerentes identificaram três novos requisitos que consideraram necessários para garantir a conformidade do quadro jurídico de vigilância com a Convenção Europeia dos Direitos do Homem: (1) exigência de provas de uma suspeita razoável em relação às pessoas alvo da interceptação; (2) autorização judicial prévia; e a (3) subsequente notificação da vigilância. Estes requisitos não foram estabelecidos no caso WEBER em virtude de o ordenamento jurídico interno alemão à época já os exigir no momento da aplicação do método oculto de investigação (escutas telefônicas, naquele caso), ao contrário da legislação britânica.

Por fim, também foi alegada a desproporcionalidade da seção 8(4) da Regulation of Investigatory Powers Act, por entenderem que os serviços de inteligência estavam coletando sistematicamente, em grande escala, não somente o conteúdo das comunicações em si mas também dados secundários de questionável necessidade para fins investigativos - como o histórico de navegação na Internet do indivíduo e a localização física do sistema vigiado -, retendo-os para a criação de um índice a fim de viabilizar pesquisas e usos futuros.

\section{b) Governo do Reino Unido}

O Governo do Reino Unido, por sua vez, alegou que as informações e a intelligence obtidas sob o abrigo da seção 8(4) da Regulation of Investigatory Powers Act eram essenciais para a proteção do Reino Unido contra ameaças à segurança nacional, particularmente, porém não de modo exclusivo, a ameaça do terrorismo. Como argumento, apontou a sofisticação dos terroristas e criminosos e a assimilação das novidades tecnológicas às suas práticas criminosas, especialmente a utilização de medidas antiforenses como modo de impedir a detecção das suas atividades (através da criptografia ou então de programas e sistemas informáticos de comunicação personalizados). A imposição de novas garantias, reivindicadas pelos requerentes, prejudicaria a capacidade do Estado em garantir a segurança nacional e de combater crimes de especial gravidade, especialmente em uma era em que os avanços nas tecnologias de comunicação aumentaram a ameaça de terrorismo praticado através da 
Internet. O requerido defendeu que, em observância à Convenção Europeia dos Direitos do Homem, cabia aos Estados avaliar as medidas necessárias para proteger a sociedade de tais ameaças, salientando que as interceptações em massa (inclusive aquelas promovidas nos cabos de fibra óptica que estruturam a Internet) são fundamentais para a descoberta de ameaças e dos seus possíveis responsáveis.

Por fim, o Governo entendeu que as interceptações encontravam previsão legal na Regulation of Investigatory Powers Act e que atendiam os requisitos oriundos do caso WEBER, pois havia previsão dos casos que admitiam o recurso à interceptação, das pessoas que poderiam ser alvo da medida ${ }^{15}$; disposições sobre os limites da medid $a^{16}$; regulamentação sobre o acesso e análise das informações (nenhum dado poderia ser lido, visto ou escutado por uma pessoa sem a autorização prévia do Secretário de Estado para a análise); disposições sobre a eliminação dos dados e destruição dos suportes físicos em que as informações estivessem preservadas ${ }^{17}$; e regulamentação sobre a divulgação e comunicação dos dados obtidos a outros Estados e serviços de inteligência ${ }^{18}$.

\section{B. Ratio decidendi}

A Corte começou por ressaltar que qualquer interferência aos direitos contidos no artigo 8. ${ }^{\circ}$ da Convenção Europeia dos Direitos do Homem somente pode ser justificada, ao abrigo do $\S 2 .^{\circ}$ do artigo $8 .^{\circ}$ da Convenção, caso haja previsão legal e constitua uma providência necessária, em uma sociedade democrática, para alcançar os fins legítimos contidos no $§ 2 .^{\circ}$ do referido artigo (a segurança nacional, a segurança pública, o bem-estar económico do país, a defesa da ordem e a prevenção das infrações penais, a proteção da saúde ou da moral ou a proteção dos direitos e das liberdades de terceiros). Por "previsão legal", o Tribunal tem

15 De acordo com o Governo, os mandados previstos na seção 8(4) da Regulation of Investigatory Powers Act eram voltados à interceptação de comunicações externas, embora em determinados casos, relacionados ao mandado e sempre que necessário para interceptar comunicações externas, a interceptação de comunicações internas também fosse permitida.

16 O Governo defendeu que os parágrafos 6.22 a 6.24 do Interception of Communications Code, conjugados com as seções 8 e 9 da Regulation of Investigatory Powers Act, eram suficientes para suprir as disposições sobre os limites temporais das interceptações.

17 Foi defendido que tanto a Regulation of Investigatory Powers Act quanto o Interception of Communications Code possuíam disposições sobre a matéria.

18 O requerido defendeu que a seção 15 (2) da Regulation of Investigatory Powers Act previa as precauções a serem tomadas referente à comunicação dos dados a outras partes, salientando que somente o que era considerado "necessário" para a finalidade autorizada poderia ser divulgado. Os parágrafos 7.4 e 7.5 do Interception of Communications Code, no entendimento do Governo, eram suficientes na regulamentação da comunicação dos dados obtidos a outros Estados, os quais estabelecem a necessidade de adoção pelos serviços de inteligência de medidas razoáveis para garantir que as autoridades do Estado estrangeiro tenham ou mantenham os procedimentos necessários para preservar o material interceptado, bem como garantir a sua divulgação, cópia, distribuição e retenção apenas na extensão mínima necessária. 
entendido ${ }^{19}$ ser necessária não somente uma base legal específica que preveja a restrição de um direito, mas também a clareza da lei, devendo ser acessível a todos os cidadãos e previsível quanto aos seus efeitos.

Em linhas gerais, o Tribunal considera que a previsão legal, ou a previsibilidade da lei - especialmente em casos de vigilância secreta e meios ocultos de investigação -, não diz respeito à possibilidade de o indivíduo a ser vigiado poder antecipar a vigilância e adaptar a sua conduta da maneira que julgar mais adequada, mas sim à necessidade de minucioso e claro detalhamento das regras referentes à medida, de modo a proteger o indivíduo do exercício arbitrário de medidas restritivas de direitos pelas autoridades responsáveis pela investigação.

Os constantes desenvolvimentos tecnológicos - os quais permitem a criação de novas ferramentas e técnicas de investigação a todo o instante - dão uma nova importância à referida exigência no contexto atual social.

Nos casos que envolvem interceptação de comunicações em investigações criminais, o Tribunal vem efetuando a análise da conformidade da lei interna com a Convenção a partir dos seis requisitos mínimos ${ }^{20}$ estabelecidos no caso WEBER AND SARAVIA V. GERMANY, previamente mencionados. Estes requisitos devem também ser observados nos casos em que a interceptação tiver como uma das finalidades a segurança nacional.

No que concerne à característica de a restrição aos direitos fundamentais constituir "uma providência necessária, em uma sociedade democrática", atentou-se ao fato de os Estados possuírem uma margem de apreciação para definir os meios e ferramentas que julgam aptos para assegurar a proteção da segurança nacional, margem esta que deve ser mais estreita caso haja a preferência à adoção do recurso de interceptação de comunicações. Esta margem está sujeita à supervisão dos tribunais europeus, devendo as autoridades estatais, ao efetuarem juízo sobre os meios de investigação a serem adotados, utilizarem como critérios em sua ponderação os princípios, os seis requisitos mínimos e as garantias estabelecidos pelo Tribunal Europeu de Direitos do Homem, além das disposições da legislação interna, de modo a impedir o abuso de poder e atentados à democracia travestidos na justificativa de salvaguarda da segurança nacional. Destarte, devem os Estados optar por

19 Quanto ao assunto, ver, entre outros, Roman Zakharov v. Russia (n. ${ }^{\circ} 47143 / 06$, julgado em ol de dezembro de 2015); Weber and Saravia v. Germany (n..$^{\circ}$ 54934/oo, julgado em 29 de junho de 2006); Rotaru v. Romania (n. ${ }^{\circ} 28341 / 95$, julgado em 04 de maio de 2000), todos julgados pelo Tribunal Europeu dos Direitos do Homem.

20 Relembramos: (1) definição de um catálogo de crimes que admitem o recurso à interceptação; (2) definição das pessoas que podem ter suas comunicações interceptadas; (3) limites e duração da interceptação; (4) os procedimentos que devem ser observados no tratamento dos dados obtidos (análise, uso e preservação das informações); (5) precauções a serem tomadas na comunicação dos dados a outras partes; (6) circunstâncias em que o material interceptado pode ou deve ser apagado ou destruído. 
A utilização de novas tecnologias no âmbito da investigação criminal e as suas limitações legais...

EDUARDO BOLSONI RIBOLI

métodos investigativos menos gravosos e somente recorrer aos mais intrusivos e restritivos quando aqueles forem insuficientes e estes revelarem-se indispensáveis.

Somente nos casos em que a legislação segue essas diretrizes é que o Tribunal Europeu dos Direitos do Homem reconhece que há qualidade de lei (quality of law): uma lei acessível, clara, previsível e dotada de garantias que legitimam a restrição de direitos fundamentais. Foi exatamente esta qualidade que os requerentes questionaram, a quality of law da seção 8(4) da Regulation of Investigatory Powers Act, em particular a sua acessibilidade e previsibilidade. A Corte cingiu-se à análise - no que tange à discussão proposta neste estudo -, da qualidade da referida lei britânica; da sua acessibilidade; da sua previsibilidade e da sua necessidade, tendo como base os seis requisitos mínimos previamente mencionados.

\section{a) Análise da acessibilidade, previsibilidade e necessidade da Regulation of Investigatory Powers Act}

Seguindo o seu entendimento originado e reafirmado em casos pretéritos ${ }^{21}$, a Corte observou que os Estados não precisam tornar público todos os detalhes de um regime de vigilância secreta - as particularidades "abaixo da linha d'água" (below the waterline) -, pois tratam-se de características inerentes à atividade secreta. Basta que tais informações estejam disponíveis de modo suficiente em domínio público. São as disposições "acima da linha d'água" (above the waterline) que devem ser dotadas de previsibilidade, tendo como referência os seis requisitos mínimos estabelecidos no caso WEBER e fatores adicionais relacionados às medidas de vigilância secreta identificados no caso ZAKHAROV V. RUSSIA (n. ${ }^{\circ}$ 47143/o6) - em que o requerente alegou que a legislação russa viabilizava a instalação de equipamentos que permitiam a interceptação de comunicações telefônicas pelo serviço de inteligência russo sem prévia autorização judicial, violando o direito à privacidade de suas comunicações telefônicas (artigo 8. ${ }^{\circ}$ da Convenção Europeia dos Direitos do Homem) -, a saber: a supervisão da medida, os mecanismos de notificação da interceptação e os instrumentos legais internos que possibilitem o questionamento da legalidade da vigilância.

Quanto ao primeiro requisito mínimo, considerou-se que a condição de previsibilidade não obriga os Estados a nomearem de forma exaustiva os crimes específicos aos quais o recurso à interceptação de comunicações pode ser aplicado, desde que presentes informações suficientes sobre a natureza das infrações em questão. A Corte já se posicionou, inclusive, contra a excessiva rigidez na redação do catálogo de crimes que admitem o uso 
de determinadas medidas de investigação ${ }^{22}$, de modo a possibilitar que a legislação acompanhe as mudanças tecnológicas e sociais. No presente caso, restou assentado que as ameaças à segurança nacional são imprevisíveis e podem se apresentar de diferentes modos, o que dificulta a sua definição prévia.

Os termos "segurança nacional" (national security) e "crime grave" (serious crime) contidos na legislação britânica foram considerados suficientemente claros, garantindo aos cidadãos indicações adequadas das circunstâncias em que as interceptações podem ser efetuadas.

Quanto ao termo national security, o Tribunal recordou que no caso KENNEDY v. THE UNITED KINGDOM (n. ${ }^{\circ}$ 26839/05) - em que, em suma, foi alegada violação da lei britânica à Convenção Europeia dos Direitos do Homem em virtude de suspeita de que as comunicações telefônicas e eletrônicas (e-mail) do requerente estavam sendo interceptadas pelo serviço de inteligência britânico devido ao seu pretérito envolvimento político em campanhas contra erros e abusos do sistema de justiça do Reino Unido - o Comissário para a Interceptação de Comunicações (Interception of Communications Commissioner) adotou, à época, a seguinte definição para o termo: "[atividades] que ameacem a segurança ou bem-estar do Estado e que visem enfraquecer ou derrocar a democracia parlamentar por meios políticos, industriais ou violentos" ${ }^{23}$.

Já o termo serious crime estava previsto, de modo compreensível, na seção 81(2)(b) da Regulation of Investigatory Powers Act (a qual faz remissão aos n..$^{\circ}$ (3)(a) e (b) da seção 81): crimes em que a pena máxima prevista seja de três ou mais anos; ou então crimes que envolvam o uso de violência, que possam resultar em ganhos financeiros substanciais ou que sejam cometidos por um elevado número de agentes em desígnio comum ${ }^{24}$.

Quanto ao segundo requisito, relacionado às pessoas suscetíveis a terem as suas comunicações interceptadas, restou reconhecido que os cabos de fibra óptica interceptados não eram escolhidos de forma aleatória, dava-se preferência aos canais de comunicações externos que tinham mais probabilidade de conduzir informações de interesse dos serviços de

22 Sobre o assunto, recomendamos, entre outros, a consulta aos casos Szabó and Vissy $v$. Hungary (n. ${ }^{\circ}$ 37138/14, julgado em 12 de janeiro de 2016) e Kokkinakis $v$. Greece (n. ${ }^{\circ} 14307 / 88$, julgado em 25 de maio de 1993), ambos julgados pelo Tribunal Europeu dos Direitos do Homem.

23 Tradução nossa. No original: "[activities] which threaten the safety or well-being of the State, and which are intended to undermine or overthrow Parliamentary democracy by political, industrial or violent means".

24 Section 81. General interpretation. “(...) (2)In this Act- (...) (b) references to serious crime are references to crime that satisfies the test in subsection (3)(a) or (b). (3)Those tests are- (a) that the offence or one of the offences that is or would be constituted by the conduct is an offence for which a person who has attained the age of twentyone and has no previous convictions could reasonably be expected to be sentenced to imprisonment for a term of three years or more; (b) that the conduct involves the use of violence, results in substantial financial gain or is conduct by a large number of persons in pursuit of a common purpose". 
A utilização de novas tecnologias no âmbito da investigação criminal e as suas limitações legais...

EDUARDO BOLSONI RIBOLI

inteligência. Característica que, na opinião dos julgadores, não significa que os serviços de inteligência interceptavam a comunicação de todas as pessoas.

Contudo, as salvaguardas que regem a eleição dos canais de comunicação a serem interceptados e a seleção do material obtido foram consideradas precárias, não sendo suficientemente robustas para fornecer garantias adequadas contra abusos. Demonstrou-se uma nítida preocupação quanto à ausência de supervisão independente dos identificadores e dos critérios de busca utilizados na filtragem das comunicações interceptadas. A possibilidade de irrestrita busca e exame de "dados de comunicação acessórios" 25 (informações como a localização virtual ou física do equipamento interceptado - através do IP do equipamento ou de informações obtidas pelo uso de GPS, por exemplo -, a identificação do remetente e do destinatário de mensagens e dados do usuário sobre navegação na Internet) foi criticada pela Corte, que não restou convencida de que a colheita de tais dados era menos intrusiva que a obtenção do efetivo conteúdo da comunicação interceptada. Isso porque o conteúdo de uma comunicação eletrônica pode ser criptografada e, caso seja desencriptada, pode não revelar dados de interesse aos serviços de inteligência. Já os dados de comunicação acessórios, por outro lado, têm o potencial de revelar dados sensíveis dos participantes da comunicação. Nestes termos, reconheceu-se que as autoridades britânicas não efetuaram um justo equilíbrio entre os interesses públicos e os direitos individuais em conflito.

Os limites temporais da interceptação foram considerados adequados, com destaque à seção 9 da Regulation of Investigatory Powers Act, a qual previa limitações bem definidas (seis meses para a investigação de crimes que atentem à segurança nacional ou econômica; e três meses para a prevenção de crimes graves), garantias suficientes para impedir o abuso da medida.

Foram também julgados adequados os procedimentos e precauções que deveriam ser observados no tratamento dos dados obtidos (análise, uso e preservação dos conteúdos angariados). Os profissionais responsáveis pela análise das informações - especificamente autorizados e devidamente treinados para esta finalidade, conforme o parágrafo 7.15 do Interception of Communications Code - somente procediam ao exame do conteúdo selecionado pelo índice automaticamente criado pelos indicadores. Restava ab initio, portanto, afastada a análise dos materiais fora do índice, ou banco de dados, até mesmo porque estes eram descartados automaticamente. Ainda, os analistas somente estavam autorizados a examinar o conteúdo mediante a elaboração de um relatório prévio que elencasse os motivos legitimadores para tal exame, devendo demonstrar se a informação poderia ser obtida por outros meios de prova menos intrusivos. 
As garantias quanto às precauções a serem tomadas na comunicação dos dados a outras partes também foram consideradas adequadas. As disposições contidas na seção 15 da Regulation of Investigatory Powers Act e no capítulo $7 .^{\circ}$ do Interception of Communications Code foram consideradas suficientemente eficazes para impedir abusos. Os referidos diplomas legais estabeleciam, em suma, que enquanto preservados, o acesso aos materiais ou dados deve ser limitado ao mínimo necessário para os "fins autorizados" ${ }^{26}$, estando sujeito a determinadas regras: limitação da partilha às partes às quais as informações foram divulgadas ou disponibilizadas; limitação até à extensão em que os dados foram divulgados ou disponibilizados; limitação à extensão da cópia do material ou dado; limitação ao número de cópias efetuadas. Nos casos em que o material interceptado for compartilhado com países ou territórios fora do Reino Unido, os serviços de inteligência britânicos devem assegurar que as autoridades às quais o conteúdo foi partilhado possuam (e observem) procedimentos estabelecidos para salvaguardar o material interceptado, garantindo que seja feita cópia, distribuição e retenção apenas na extensão mínima necessária, não podendo o material ser divulgado novamente para terceiros sem a explícita autorização dos serviços de inteligência britânicos, sendo necessária a devida destruição das informações após o uso para o qual foram colhidas.

As disposições acerca da eliminação e da destruição dos dados contidas na Regulation of Investigatory Powers Act e complementadas pelo Interception of Communications Code também foram consideradas suficientemente claras. As cópias do material obtido deveriam ser destruídas assim que não fossem mais necessárias para os fins previstos na seção 5(3) da Regulation of Investigatory Powers Act ${ }^{27}$; o conteúdo deveria ser mantido por até dois anos (e apagado por um processo de eliminação automático após o término do segundo ano); e deveria ser realizada uma avaliação, em intervalos apropriados, para confirmar se a retenção do conteúdo mantinha-se justificada.

No que toca à proporcionalidade das interceptações em massa, embora este meio de investigação possa provocar graves restrições aos direitos individuais ele também pode ser

26 De acordo com a seção 15 da Regulation of Investigatory Powers Act e parágrafo 7.2 do Interception of Communications Code, informações ou dados são considerados necessários para "fins autorizados" se continuarem a ser, ou for provável que se tornem, necessários ("if it continues to be, or is likely to become") para os fins mencionados na seção 5 (3) da Regulation of Investigatory Powers Act (interesses de segurança nacional; prevenção ou detecção de crimes graves; salvaguarda do bem-estar econômico do Reino Unido; cooperação internacional em casos de criminalidade grave); facilitar a realização das funções de interceptação promovidas pelo Secretário de Estado; facilitar o desempenho das funções do Comissário para a Interceptação de Comunicações ou do Tribunal de Poderes Investigatórios (IPT); para garantir ao órgão acusador as informações necessárias para conduzir a ação penal em observância ao devido processo legal; ou para o desempenho de funções impostas a qualquer pessoa sob a legislação de registros públicos (§ $365^{\circ}$ da decisão).

27 Em suma, interesses de segurança nacional; prevenção ou detecção de crimes graves; salvaguarda do bem-estar econômico do Reino Unido; cooperação internacional em casos de criminalidade grave. 
A utilização de novas tecnologias no âmbito da investigação criminal e as suas limitações legais...

EDUARDO BOLSONI RIBOLI

considerado uma estratégia valiosa para atingir os objetivos legítimos perseguidos, particularmente em virtude do atual nível de ameaça do terrorismo global e da criminalidade grave. A Corte reconheceu que a medida é proporcional com base nos relatórios do Independent Reviewer of Terrorism Legislation - o qual apontou o perigo apresentado por ferramentas informáticas sofisticadas que impedem a detecção de atividades por meios tradicionais de investigação e alertou a imprevisibilidade da rota que uma comunicação utiliza devido à natureza global da Internet - e da Comissão de Veneza (de março de 2015) - que reconheceu o intrínseco valor da interceptação em massa para operações de segurança por permitirem que os serviços de inteligência e de segurança adotem uma abordagem proativa na investigação de ameaças até então desconhecidas. ${ }^{28}$

Em relação à revisão, supervisão e notificação da vigilância, considerou-se que estas podem ocorrer em três momentos distintos: na ocasião de sua requisição, durante a sua implementação e após o seu término. Afastou-se qualquer possibilidade de questionamento ou supervisão nos dois primeiros momentos, para salvaguardar o sigilo da investigação e assegurar sua eficácia. Assim, a interceptação somente poderia ser questionada após o seu término, preferencialmente perante uma autoridade judicial, nos moldes da lei interna (como ocorre no Reino Unido com o Investigatory Powers Tribunal).

Estas considerações levaram o Tribunal a concluir que no caso BIG BROTHER WATCH as interceptações em massa foram realizadas dentro da margem de apreciação conferida aos Estados. Embora tenha reconhecido haver regulamentação sólida para esta modalidade de interceptação, duas áreas principais causaram preocupação: (1) a ausência de supervisão de todo o processo de seleção, incluindo a escolha dos cabos ou canais de comunicação a serem interceptados, os indicadores e critérios de busca para a filtragem das comunicações interceptadas e a seleção de material para exame por um analista; e (2) a ausência de salvaguardas aplicáveis à seleção de dados de comunicações acessórios para análise.

Por todas estas razões, em especial às duas deficiências destacadas anteriormente, o Tribunal Europeu dos Direitos do Homem considerou que o regime da seção 8(4) da Regulation of Investigatory Powers Act não atendia ao requisito da quality of law, sendo incapaz de manter a sua interferência no que é "necessário, em uma sociedade democrática", confirmando violação do artigo $8 .^{\circ}$ da Convenção Europeia dos Direitos do Homem.

\section{b) Acréscimo de novos requisitos mínimos}

Embora não tenha negado o impacto das tecnologias modernas na intrusão das interceptações, a Corte Europeia dos Direitos do Homem não considerou serem as interceptações em 
A utilização de novas tecnologias no âmbito da investigação criminal e as suas limitações legais...

EDUARDO BOLSONI RIBOLI

massa mais intrusivas na vida privada de um indivíduo do que a interceptação tradicional (direcionada), por entender que desta última pode resultar mais material sobre a vida do indivíduo e suas comunicações.

O Tribunal reconheceu que os requisitos mínimos adicionais propostos pelos requerentes podem constituir garantias importantes em determinados casos, porém não considerou apropriado adicioná-los aos seis já existentes. No que tange à exigência de provas de uma suspeita razoável em relação às pessoas alvo da interceptação e a sua subsequente notificação, o acréscimo de tais requisitos seria inconsistente quanto ao respeito à margem de apreciação dos Estados em definir os meios e ferramentas que julgam aptos para assegurar a proteção da segurança nacional. A interceptação em massa, por definição, não possui alvos pré-definidos e dessa forma ambos requisitos tornar-se-iam obstáculos à aplicação da medida, já que pressupõem a existência de alvos de interceptação claramente definidos.

Quanto à exigência de autorização judicial prévia, o Tribunal não encontrou nenhuma incompatibilidade com a interceptação de comunicações - reconhecendo, inclusive, se tratar de uma "importante garantia contra arbitrariedades" 29 -, porém julgou ser um requisito desnecessário. Isso porque em diferentes países europeus, como no Reino Unido, há a possibilidade de questionar a legalidade da interceptação posteriormente pela via judicial. A possibilidade de supervisão independente - por agentes especializados não envolvidos com a investigação, por exemplo - supriria a autorização judicial prévia, o que, no entendimento do Tribunal, constitui uma garantia contra abusos. A autorização judicial prévia não necessariamente impediria a "possibilidade de ação imprópria por um agente desonesto, negligente ou excessivamente zeloso" ${ }^{30}$, como observado no caso RoMAN ZAKHAROV. São mais importantes, na verdade, a atenção ao real funcionamento do sistema de interceptação, a observância ao sistema de pesos e contrapesos sobre o exercício do poder e a existência ou ausência de qualquer evidência de verdadeiro abuso (como a autorização de interceptações a esmo, de forma irregular ou sem a devida e apropriada consideração dos interesses e direitos em conflito).

\section{Análise crítica}

Narrados os principais fundamentos do julgamento, é perceptível que se trata de um julgamento paradigmático, podendo ser considerado, até certo ponto, uma vitória do direito fundamental à privacidade sob meios ocultos de investigação. Demonstra-se louvável o reconhecimento por parte do Tribunal Europeu dos Direitos do Homem de que as intercep-

29 Tradução nossa. No original: "important safeguard against arbitrariness" (§ 318. a da decisão).

30 Tradução nossa. No original: "the possibility of improper action by a dishonest, negligent or over-zealous official" (§ $319 .^{\circ}$ da decisão). 
A utilização de novas tecnologias no âmbito da investigação criminal e as suas limitações legais...

EDUARDO BOLSONI RIBOLI

tações possuem um elevado potencial intrusivo, seja na sua modalidade em massa, seja na direcionada, principalmente em razão da possibilidade de obtenção de dados de comunicação acessórios.

$\mathrm{Na}$ atual era da sociedade da informação (digital), a interceptação não se restringe mais à lógica da interceptação tradicional. Hoje a pluralidade de sistemas informáticos e dispositivos eletrônicos e a sua adoção por grande parte da sociedade permitem que o Estado obtenha muitos mais dados quando aplica medidas de vigilância. As informações que podem ser obtidas são quase infindáveis, além dos elementos clássicos como a palavra falada e a palavra escrita, atualmente é possível obter uma vasta gama de informações sobre o indivíduo, algumas mais sensíveis que outras, como: documentos eletrônicos, palavras-passe, localização, monitoramento em tempo real do indivíduo e do conteúdo inserido ou digitado no sistema ou dispositivo. As informações disponíveis dependem, primeiramente, do dispositivo eletrônico ou do sistema informático interceptado e, em segundo lugar, da técnica ou da ferramenta utilizada na investigação.

A estrutura dos canais de comunicações - pense-se aqui sobretudo ao vasto fluxo informacional que percorre os cabos de fibra óptica que estruturam a Internet -, o desenvolvimento de novas tecnologias e sistemas informáticos e a proliferação e adesão massiva de dispositivos eletrônicos - os quais se tornaram, em muitos casos, ferramentas essenciais, ou umbilicais, para o desenvolvimento de inúmeras tarefas, das mais banais até as mais intricadas - são fatores que devem ser sopesados atualmente no contexto das interceptações de comunicações.

Todos estes motivos levam-nos a discordar do Tribunal quanto à dispensabilidade da atualização dos requisitos mínimos, originados no caso WEBER, a serem observados na aplicação de uma medida de interceptação, bem como da prescindibilidade da criação de novas exigências. A realidade tecnológica e social à época em que o caso foi julgado (29 de junho de 2006) não guarda mais relação com a atual, o salto tecnológico dado desde então foi significativo. O escopo das (ferramentas utilizadas nas) interceptações naquela ocasião era patentemente mais restrito que aquele viabilizado pelas ferramentas de investigação atuais.

Independentemente da modalidade e da finalidade, a interceptação de comunicações é uma medida dotada de um inerente potencial intrusivo nos direitos fundamentais também dos indivíduos não relacionados à investigação, especialmente quando se trata de interceptação em massa, em que há uma ampla recolha de informações sem qualquer diferenciação entre os alvos, com a colheita de informações sobre pessoas não relacionadas a crimes graves ou ao terrorismo (podendo inclusive adentrar em esferas protegidas por sigilo profissional). Evidentemente, o terrorismo e outras modalidades de crimes graves são uma 
A utilização de novas tecnologias no âmbito da investigação criminal e as suas limitações legais...

EDUARDO BOLSONI RIBOLI

ameaça real no mundo atual, perigos que não podem, contudo, ser invocados oportunisticamente como se fossem um estandarte para a adoção de medidas altamente restritivas a direitos fundamentais, em especial para a averiguação de ameaças amplas como a segurança nacional ou o bem-estar econômico do Estado, sem estarem tais medidas submetidas a verdadeiras garantias contra abusos, como ressaltado no voto dissidente do Juiz Koskelo no julgamento do caso BIG BROTHER WATCH ${ }^{31}$.

Não concordamos com o entendimento do Tribunal, em especial, quanto à desnecessidade de uma autorização judicial prévia e de elementos que confirmem a suspeita da ameaça como requisitos extras aos seis já existentes. Em função do potencial lesivo a direitos fundamentais inerente a uma interceptação de comunicações e a possibilidade de abusos da medida, julgamos indispensável a exposição dos motivos que fundamentam o recurso à interceptação. O controle posterior, como ocorre no Reino Unido, é, ao nosso ver, uma importante garantia, porém insuficiente, per se, para a proteção de abusos durante a aplicação da medida. A má aplicação do recurso à interceptação ab initio pode invalidar por completo todo o esforço investigativo, tornando nulas as provas obtidas em desconformidade com as orientações constitucionais, com possíveis efeitos-à-distância ${ }^{32}$. $\mathrm{O}$ argumento do Tribunal de que a autorização judicial prévia não seria uma garantia suficiente não procede, porém não deve invalidar o acréscimo deste requisito, porquanto tratar-se-ia de uma salvaguarda adicional a ser observada na implementação de um recurso excepcionalmente gravoso.

Embora os Estados devam dispor de uma margem de apreciação na escolha dos meios aptos a promover as suas atividades investigativas, principalmente nos casos que atentam à segurança nacional, a probabilidade de abusos e a gravosa restrição a direitos fundamentais decorrentes do recurso à interceptação de comunicações impõem um estreitamento dessa margem e a designação de garantias sólidas.

A necessidade de garantias adicionais, ou no mínimo a atualização dos requisitos existentes, é evidente.

O Tribunal Europeu dos Direitos do Homem perdeu uma verdadeira chance de adaptar o seu entendimento à realidade atual e aos futuros desafios em matéria de interceptação de comunicações e vigilância em geral.

$31 \S \S 11 .^{\circ}$ a $15 .^{\circ}$ do voto dissidente do Juiz Koskelo.

32 "[A]s provas que atentam contra os direitos de liberdade arrostam com um efeito-à-distância que consiste em tornarem inaproveitáveis as provas secundárias a elas causalmente vinculadas" (MENDES, Paulo de Sousa - O efeito-à-distância das proibições de prova. In Revista do Ministério Público do RS. Porto Alegre. [ISSN]. N. ${ }^{\circ} 74$, 2013, p. 219). 
As problemáticas decorrentes do uso de métodos ocultos de investigação não são novas ${ }^{33}$. Embora tenhamos tecido críticas ao Tribunal Europeu dos Direitos do Homem quanto à oportunidade perdida de atualizar o seu entendimento em matéria de interceptação de comunicações - e, de certa maneira, no tocante aos métodos ocultos de investigação - devemos reconhecer um certo grau de mérito do julgamento, pois fortaleceu a posição do Tribunal quanto aos requisitos mínimos a serem observados na previsão (e na aplicação) de métodos ocultos de investigação - principalmente aqueles novos oriundos do desenvolvimento tecnológico -, de modo a garantir ao máximo possível a proteção contra usos abusivos desta espécie de meio de obtenção de prova.

\section{O uso de softwares de espionagem como método oculto de obtenção de prova}

Analisaremos agora uma nova tecnologia de inestimável valia à investigação criminal, a qual tem sido paulatinamente implementada em diferentes países europeus, pese embora pouco debatida pela doutrina portuguesa ${ }^{34}$ : os softwares de espionagem.

Os softwares de espionagem ${ }^{35}$ são programas informáticos elaborados para fins de extração de dados contidos em um sistema informático ou aparelho eletrônico sem o conhecimento ou consentimento do seu utilizador ${ }^{36}$. Tratam-se de programas que podem ser insta-

33 Remetemos o leitor às obras citadas na nota 9 para o conhecimento aprofundado das problemáticas inerentes aos métodos ocultos de investigação criminal.

34 Com exceção de David Silva Ramalho (cf. RAMALHO, David Silva - Métodos Ocultos de Investigação Criminal em Ambiente Digital. Coimbra: Almedina, 2017); Duarte Alberto Rodrigues Nunes (cf. NUNES, Duarte Alberto Rodrigues - Os Meios de Obtenção de Prova Previstos na Lei do Cibercrime. Coimbra: Gestlegal, 2018); e Benjamim Silva Rodrigues (cf. RODRIGUES, Benjamim Silva - Da Prova Penal - Tomo II - Bruscamente... A(s) face(s) oculta(s) dos métodos ocultos de investigação criminal. Cascais: Rei dos Livros, 2010), a doutrina portuguesa parece ainda não ter percebido a complexidade e gravidade das problemáticas que gravitam em torno deste novo método de obtenção de prova. Em certos casos, como ocorre com os dois últimos autores citados, há ainda a confusão de softwares de espionagem com as buscas online, métodos de obtenção de prova distintos.

35 Preferimos adotar o termo software de espionagem para evitar a redução deste programas à determinadas modalidades de softwares espiões, como é o caso dos autores que utilizam o termo "cavalo de Tróia", o qual na verdade é apenas uma das espécies de software de espionagem identificação de uma modaldiade de software de espionagem. Também afastamos o termo malware (contração de malicious software) a fim de evitar a interpretação de que todo o software de espionagem é necessariamente mal intencionado ou ilegal.

36 Cf. MARSHALL, Angus - Digital Forensics - Digital Evidence in Criminal Investigation. Chichester: WileyBlackwell, 2008, p. 66; BOLDT, Martin - Privacy-Invasive Software - Exploring Effects and Countermeasure, 2007. 138 f. Monografia de Licenciatura (Licenciatura em Ciência e Tecnologia da Computação)-Department of Systems and Software Engineering da Blekinge Institute of Technology, Karlskrona, 2007. [Consultado em: 23 de abril de 2018]. Disponível em: https://www.diva-portal.org/smash/get/diva2:837092/FULLTEXTo1.pdf, p. 10; FILIOL, Eric. Computer viruses: from theory to application. Paris: Springer, 2005, p. 83. 
lados de múltiplas formas ${ }^{37}$ (via Internet ou através de um pen-drive, por exemplo), capazes de executar diferentes funções no dispositivo monitorado, as quais variam de acordo com a sua estrutura (modalidade) e finalidade. A implementação de um software de espionagem em um sistema informático ou dispositivo eletrônico permite a extração de uma vasta gama de dados, desde documentos, palavras-passe, localização física, até mesmo monitoramento audiovisual em tempo real e informações biométricas do usuário guardadas no sistema (como os dados guardados necessários para o reconhecimento facial para desbloqueio e uso de um smartphone, por exemplo). A depender da modalidade de softwares de espionagem instalado, é possível até mesmo efetuar alterações nas informações contidas no dispositivo investigado ${ }^{38}$. Trata-se de um método de investigação mais intrusivo e potencialmente mais eficaz que uma mera interceptação de comunicações.

Por se tratarem de programas instalados e executados de forma sub-reptícia, os softwares de espionagem apresentam um valor ímpar como ferramenta de investigação criminal: permitem a obtenção de múltiplas informações antes de sua eliminação ou ocultação por medidas antiforenses.

Perceptível, desde já, a gravidade que estes softwares representam a direitos fundamentais. Em razão da sua mais valia à investigação criminal, dos conflitos que o seu uso gera entre os interesses da Justiça e da sua patente restrição de direitos, diferentes países europeus vêm implementando com cautela e com a devida densificação normativa este novo método de obtenção de prova em seus ordenamentos jurídicos, de forma a viabilizar o uso deste novo meio de obtenção de prova da maneira menos intrusiva a direitos e liberdades fundamentais, garantindo, ao mesmo tempo, a proteção destes.

\section{A. Alguns exemplos do uso de software de espionagem na Europa}

Talvez o exemplo que melhor ilustre a problemática da assimilação de novas tecnologias para a criação de novos métodos de obtenção de prova seja o exemplo alemão ${ }^{39}$. O legislador alemão vem tentando regulamentar o uso de software de espionagem (conhecido como Bundestrojaner) desde 2006, quando a sua utilização foi viabilizada por uma alteração na Lei de Proteção da Constituição da Renânia do Norte-Vestfália para fins de proteção a ameaças

37 RAMALHO, David Silva - O uso de malware como meio de obtenção de prova em processo penal. Revista de Concorrência e Regulação. Lisboa. ISSN 1647-5801. A. IV, N. ${ }^{\circ}$ 16, 2013, pp. 205-207; CLOUGH, Jonathan - Principles of Cybercrime. Cambridge: Cambridge University Press, 2010, p. 32.

38 FILIOL, Eric. Op. cit., p. 83; CLOUGH, Jonathan. Op. cit., pp. 32 e 34.

39 Para mais informações sobre o software de espionagem para fins investigativos na Alemanha, cf. FORGÓ, Nikolaus; HAWELLEK, Christian; KNOKE, Friederike; STOKLAS, Jonathan - The Collection of Electronic Evidence in Germany: A Spotlight on Recent Legal Developments and Court Rulings. In: New Technology, Big Data and the Law. Singapore: Springer Nature, 2017, p. 251-279. 
A utilização de novas tecnologias no âmbito da investigação criminal e as suas limitações legais...

EDUARDO BOLSONI RIBOLI

à livre ordem democrática fundamental ou à continuada existência ou segurança da Federação. Contudo, em 27 de fevereiro de 2008 o Tribunal Constitucional alemão julgou ${ }^{40}$ a referida alteração legislativa inconstitucional, porquanto, em suma, violava direitos e princípios fundamentais, como o direito geral à personalidade, o princípio da segurança jurídica, o princípio da proporcionalidade e a falta de salvaguardas suficientes para assegurar a proteção da área central da vida privada. Neste mesmo julgamento, o Tribunal Constitucional criou um novo direito fundamental: a confidencialidade e integridade de sistemas informáticos, o qual tem como finalidade a proteção do interesse do usuário em garantir que os dados criados, processados e armazenados por um sistema informático acobertados pelo seu âmbito de proteção restem confidenciais. Naquela decisão, o Tribunal estabeleceu diretrizes constitucionalmente orientadas para uma futura regulamentação deste novo método de obtenção de prova na Alemanha.

Em 25 de dezembro de 2008 entrou em vigor na Alemanha a Bundeskriminalamtgesetz (BKAG), lei editada em observância às orientações do Tribunal Constitucional, prevendo o uso de softwares de espionagem para fins de prevenção e investigação em crimes relacionados ao terrorismo. Contudo, em 20 de abril de 2016, o Tribunal Constitucional julgou ${ }^{41}$ inconstitucionais as disposições contidas no § 20k da BKAG (artigo que regulamentava o uso de software de espionagem), por não se adequarem a uma série de requisitos relacionados ao princípio da proporcionalidade e à proteção de direitos fundamentais (semelhantes aos requisitos de WEBER do Tribunal Europeu dos Direitos do Homem, como os casos que admitem a aplicação da medida; extensão da medida a terceiros; exigência de salvaguardas capazes de proteger o núcleo da vida privada, entre outros), determinando a revisão da BKAG.

A revisão da BKAG foi realizada em $1 .^{\circ}$ de junho de 2017 e entrou em vigor em 25 de maio de 2018. Atualmente, o uso de software de espionagem está regulamentado no ordenamento jurídico alemão no § 49 da BKAG, o qual prevê todas as especificidades sobre o uso deste método de investigação, como os crimes aos quais a medida é permitida (criminalidade grave e terrorismo); o seu alcance; a sua duração (limitado a um máximo de três meses, podendo ser prorrogado por igual prazo); os pressupostos de admissibilidade (requisição da autoridade competente e autorização judicial, devendo em ambos os casos haver a descrição da pessoa à qual a medida é direcionada e do sistema informático a ser vigiado); disposições sobre conservação e eliminação dos dados obtidos, entre outras particularidades. Não houve ainda pronúncia do Tribunal Constitucional sobre a conformidade constitucional 
destas novas regulamentações, contudo a simples comparação da atual versão da BKAG com a versão anterior evidencia progressos na densificação do dispositivo legal que regulamenta o Bundestrojaner.

A França prevê o uso de software de espionagem (denominado dispositif technique pelo legislador francês) para fins de investigação criminal nos artigos 706-102-1 a 706-102-9 do Code de Procédure Pénale ${ }^{42}$. Em linhas gerais, o recurso ao dispositif technique é restrito aos crimes de elevada gravidade, depende de requisição devidamente fundamentada pelo Parquet e de autorização judicial, a qual deve especificar o modo de funcionamento do software (detalhes sobre o sistema informático a ser monitorado, duração do monitoramento, modo de instalação, períodos em que pode ser ativado). O diploma processual penal francês também estabelece a obrigatoriedade de realização de relatório das operações e dispõe sobre a conservação e destruição do conteúdo obtido.

$\mathrm{Na}$ Espanha ${ }^{43}$, o uso de software de espionagem encontra previsão legal no $\mathrm{n} .{ }^{\circ} 1$ do artigo 588 septies $a$, suplementado pelos artigos 588 septies a ao 588 bis k, todos da Ley de Enjuiciamiento Criminal. Assim como ocorre no ordenamento jurídico francês, a legislação espanhola prevê os crimes que admitem este recurso, estabelecendo também a necessidade de requisição e decisão, devidamente fundamentadas, devendo a decisão que autoriza a medida especificar o seu modo de funcionamento (a modalidade de software de espionagem a ser empregada, o alcance do software espião, o modo como os dados serão obtidos e preservados, os agentes autorizados a implementá-lo, a sua duração, a sua documentação, a conservação dos dados angariados).

$\mathrm{Na}$ Itália ${ }^{44}$, o uso de software de espionagem para fins de investigação criminal encontra previsão legal desde o início de 2018. O captatore informatico, como é conhecido na Itália, está disposto no artigo $266, \mathrm{n}^{\circ} 2$ e artigos seguintes do Código de Processo Penal. O capta-

42 Para um estudo mais aprofundado do sistema de interceptação de comunicações francês e uma análise sobre o uso do dispositif technique no processo penal francês, cf. FÈVRE, Paul Le - Il regime della captazzione dei dati informatici nel diritto francese. In Parola alla Difesa. Pisa. ISSN 2531-680X. N. ${ }^{\circ} 1,2016$, p. 181-183; HUYGHE, François-Bernard - Les Écoutes Téléphoniques. Paris: Presses Universitaires de France, 2009; GUERRIER, Claudine - Révision du code de procédure pénale 2016: le nouveau régime des interceptions électroniques. [Consultado em: 02 de Outubro de 2018]. Disponível em: http://www.juriscom.net/wp-content/ uploads/2016/10/20161026penalcomm.pdf.

43 Para mais informações sobre o uso software de espionagem no ordenamento jurídico espanhol, cf. COLOMER, Juan-Luis Gómez - El processo penal español a comienzos del siglo XXI. Diagnóstico sobre sus principales problemas y propuesta de posibles soluciones, al hilo de la lucha contra la criminalidad organizada y la persecución de los delitos de corrupción. In InDret. Barcelona. ISSN 1698-739X. N. ${ }^{\circ}$ 1, 2017, p. 1-59; PRADIILLO, Juan Carlos Ortiz - La investigación del delito en la era digital: Los derechos fundamentales frente a las nuevas medidas tecnológicas de investigación - Estudios de Progreso - Fundación Alternativas. Madrid: Fundación Alternativas, 2013.

44 Para mais informações sobre o uso software de espionagem no ordenamento jurídico italiano, cf. FELICIONI, Paola - Lacquisizione da remoto di dati digitali nel procedimento penale: evoluzione giurisprudenziale e prospettive di riforma. Processo Penale e Giustizia. Torino. ISSN 2039-4527. N. ${ }^{\circ}$ 5, 2016, p. 118-138; FILIPPI, 
A utilização de novas tecnologias no âmbito da investigação criminal e as suas limitações legais...

EDUARDO BOLSONI RIBOLI

tore informatico é um recurso direcionado a crimes graves (como criminalidade organizada, terrorismo, tráfico de estupefacientes, entre outros), que depende da requisição do Ministério Público (com demonstração de indícios de crime e suficientes justificativas para a imprescindibilidade da medida e a duração pretendida da medida) e de autorização judicial (a qual deve detalhar todo o funcionamento do captatore, em especial as funções a serem ativadas). A operação deve ser documentada (implementação, uso, dados obtidos, requisições autorizações da medida e eventuais prorrogações, conservação e eliminação de dados) e deve respeitar a inviolabilidade do domicílio do investigado, a menos que hajam indícios suficientes que levem a crer que as práticas ilícitas investigadas estejam a ocorrer naquele local (este requisito não é necessário para crimes relacionados ao terrorismo ou à criminalidade organizada, os quais permitem a restrição da privacidade do domicílio do investigado).

\section{B. O software de espionagem no ordenamento jurídico português: previsão legal?}

Como modo de adequar o ordenamento jurídico interno à legislação supranacional e aos tratados internacionais, bem como na tentativa de ultrapassar os desafios decorrentes da evolução tecnológica, sobretudo em ambiente digital, o legislador português editou a Lei n. ${ }^{\circ}$ 109/2009, de 15 de setembro. A "Lei do Cibercrime" pode ser classificada como um avanço no ordenamento jurídico português. Além de compatibilizar a realidade jurídica à realidade técnica, a lei prevê novos métodos de obtenção de prova que fazem uso das tecnologias de informação, como o acesso a dados informáticos; as buscas online; a apreensão de correio eletrônico; e o recurso às ações encobertas em ambiente digital.

O artigo 19 da Lei do Cibercrime, que trata das ações encobertas em ambiente digital, dispõe em seu n. ${ }^{\circ} 2$ que: "Sendo necessário o recurso a meios e dispositivos informáticos observam-se, naquilo que for aplicável, as regras previstas para a intercepção de comunicações" 45 , abrindo discussão ${ }^{46}$ sobre a consagração do uso de software de espionagem em Portugal.

Apesar de merecedora de louvor quanto as suas demais disposições, a Lei do Cibercrime padece de atecnia legislativa ao (aparentemente) tentar introduzir novas tecnologias digitais de espionagem, nomeadamente os softwares de espionagem, para fins de investigação criminal no direito português. Embora não seja o objetivo do presente estudo analisar a conformidade constitucional do dispositivo, não podemos deixar de registrar nosso descontentamento quanto ao . $^{\circ} 2$ do artigo $19 .^{\circ}$ da referida lei. A disposição é de dúbia

L. - Lispe-perqui-intercettazione "itinerante": le Sezioni Unite azzeccano la diagnosi, ma sbagliano la terapia. Parola alla Difesa. Pisa. ISSN 2531-680X. N. ${ }^{\circ}$ 1, 2016, p. 179-181; VELANI, Luigi Gino - Trojan horse, strumenti investigativi e diritti fondamentali: alla ricerca di un difficile equilibrio. Parola alla Difesa. Pisa. ISSN 2531-680X. N. ${ }^{\circ} 1,2016$, p. 173-179.

45 Destaques nossos.

46 RAMALHO, David Silva - Métodos Ocultos de... cit., p. 338 e ss. 
A utilização de novas tecnologias no âmbito da investigação criminal e as suas limitações legais...

EDUARDO BOLSONI RIBOLI

constitucionalidade, os métodos ocultos de investigação criminal, por serem métodos relativamente proibidos de prova, reclamam uma densificação legal robusta, como vimos anteriormente. A simples previsão legal com remissão ao regime da interceptação de comunicações quando houver necessidade de suplementação é exígua. Além de serem meios de obtenção de prova nitidamente distintos, aquele regime não contém disposições específicas ao funcionamento de um software de espionagem (como as funções que podem ser ativadas, o modo como deve ser realizada a obtenção das informações ou então a instalação e remoção do sistema informático ou dispositivo eletrônico investigado). O alarmante potencial lesivo a direitos fundamentais decorrente do uso de softwares de espionagem demanda clareza, densidade e precisão na regulamentação deste recurso, o que não ocorre na atual versão da Lei do Cibercrime.

De fato, restrições a direitos fundamentais somente podem operar mediante uma interpretação constitucionalmente orientada ${ }^{47}$, de modo que só há interpretação conforme à Constituição se a restrição for justificada e adequada diante da necessidade de proteção ou promoção de um interesse constitucional, na medida da necessidade em questão ${ }^{48}$. Imperiosa, portanto, a observância ao princípio da legalidade ${ }^{49}$ em matéria de métodos de investigação criminal, principalmente quando se tratar de um método oculto. Como ensina Manuel Monteiro Guedes Valente, “A sociedade internético-personocêntrica (...) exige um melhor legislador, hermeneuta, um melhor exegeta e um melhor aplicador da norma dentro da materialidade constitucional democrática, garantista e humanista" ${ }^{50}$. Imperiosa a observância aos princípios e orientações constitucionais em matéria de produção probatória $^{51}$ - legalidade, reserva de Constituição, reserva de lei, reserva de código, segurança jurídica, determinabilidade, catálogo, excepcionalidade, entre outros - sobretudo em métodos ocultos de investigação, e ainda mais naqueles tão intrusivos quanto o uso de software de espionagem.

E aqui voltamo-nos à importância do julgamento do caso BIG BROTHER WATCH AND Others v. The United Kingdom pelo Tribunal Europeu dos Direitos do Homem. Mesmo que

47 MIRANDA, Jorge - Direitos Fundamentais. Coimbra: Almedina, 2017, p. 463.

48 ANDRADE, José Carlos Vieira de - Os Direitos Fundamentais na Constituição Portuguesa de $1976.5 .^{a}$ ed. Coimbra: Almedina, 2012, p. 287.

49 CAIRES, João Gouveia de - O registo de som e imagem e as escutas ambientais. In Direito da Investigação Criminal e da Prova. Coimbra: Almedina, 2014, p. 275

50 VALENTE, Manuel Monteiro Guedes - O Reforço dos Princípios Constitucionais na Obtenção de Prova no Mundo Digital. Corpus Delicti - Revista de Direito de Polícia Judiciária. Brasília. ISSN 2526-4265. V. 2, N. ${ }^{\circ}$, 2018, p. 23.

51 O autor faz uma acurada análise dos princípios a serem observados em matéria de métodos ocultos de obtenção de prova em VALENTE, Manuel Monteiro Guedes - O Reforço dos Princípios Constitucionais na Obtenção de Prova no Mundo Digital. Corpus Delicti - Revista de Direito de Polícia Judiciária. Brasília. ISSN 2526-4265. V. 2, N. ${ }^{\circ} 3,2018$, pp. 15-22. 
os Estados tenham uma margem de apreciação na escolha dos meios aptos a promover as suas atividades investigativas, a assimilação e a aplicação de novas tecnologias à investigação criminal somente pode ser operada em estrita observância a uma regulamentação prévia dotada de qualidade, de modo a impedir restrições abusivas e desproporcionais a direitos fundamentais. É precisamente o que não ocorre na Lei do Cibercrime, legislação portuguesa que, ao contrário dos exemplos legislativos estrangeiros, não prescreve as particularidades inerentes aos "meios e dispositivos informáticos" dos quais versa. Não há, atualmente, base legal que autorize o uso de software de espionagem para fins de prevenção ou investigação em Portugal.

\section{Conclusões}

O avanço tecnológico iniciado nas últimas décadas do século passado reestruturou incontornavelmente a vida em sociedade. O desenvolvimento e a sofisticação de novos sistemas informáticos e aparelhos eletrônicos remodelou diferentes áreas basilares do convívio em sociedade, revolucionando e facilitando, por exemplo, as práticas econômicas e comunicacionais. Há cada vez mais adesão social às tecnologias de informação, devido à praticidade que conferem à execução de incontáveis atividades, desde as mais banais até as mais complexas.

Contudo, esta funcionalidade não se restringe a atividades lícitas. Há, também, cada vez mais assimilação de novas tecnologias de informação para a perpetração de práticas ilícitas, principalmente daquelas ferramentas capazes de ocultar a atividade criminosa e/ ou evadir tentativas de investigação, o que reclama dos Estados a necessidade de idealizarem métodos de investigação capazes de contornar tais obstáculos. Surgem então novos métodos de investigação - especialmente métodos ocultos de investigação, em razão da possibilidade de antecipação de qualquer tentativa de ocultação de dados, como os softwares de espionagem -, e a imprescindibilidade do aprimoramento daqueles já existentes, como os complexos programas de interceptação de comunicações em massa empregados pelos serviços de inteligência do Reino Unido.

No caso Big Brother Watch and Others v. The United Kingdom, o Tribunal Europeu dos Direitos do Homem reconheceu o valor e também a gravidade das interceptações de comunicações (em massa e direcionadas) como métodos de investigação. Embora possam obter dados valiosos para fins preventivos e investigativos, tratam-se de recursos com alta potencialidade de restrição de diferentes direitos fundamentais (no caso BIG BROTHER WATCH, especificamente, os direitos à privacidade, previstos no artigo $8 .^{\circ}$ da Convenção Europeia dos Direitos do Homem), por serem capazes de obter informações acessórias inci- 
A utilização de novas tecnologias no âmbito da investigação criminal e as suas limitações legais...

EDUARDO BOLSONI RIBOLI

dentais que dizem respeito à vida íntima do indivíduo vigiado e de outras pessoas que com ele se comuniquem. O Tribunal solidificou a sua jurisprudência ao ressaltar a importância de previsão legal para a viabilização de métodos de investigação restritivos de direitos como as interceptações, observando, contudo, a imprescindibilidade desta base legal ser dotada de suficiente qualidade, de modo a impedir arbitrariedades.

A referida decisão é paradigmática, pois reforça não somente o entendimento do Tribunal Europeu dos Direitos do Homem como também fortalece a doutrina portuguesa e europeia que com tanto esforço vem defendendo a necessidade de adequada densificação normativa dos métodos ocultos de investigação.

Os reflexos desta decisão em matéria de (novos) meios de obtenção de prova e de utilização de novidades tecnológicas para fins de prevenção e investigação são evidentes: os Estados precisam repensar as ferramentas e os métodos investigativos que dispõem para superar os obstáculos decorrentes da assimilação de novas tecnologias pela criminalidade, para garantir eficácia na prevenção e investigação de delitos, especialmente de crimes graves e do terrorismo. Para tanto, devem também os Estados incorporar novas tecnologias ao seu aparato investigativo, porém qualquer tentativa de incorporação deve ser precedida de base legal sólida, precisa, densa, acessível, previsível e proporcional, em observância aos princípios e garantias constitucionais e supranacionais idealizados para proteger os cidadãos contra abusos do poder estatal e garantir a mínima intromissão e restrição possível a direitos fundamentais.

De forma a ilustrar a assimilação de novas tecnologias para fins de investigação, trouxemos o exemplo dos softwares de espionagem, instrumentos que contornam todos os obstáculos referidos e possibilitam a eficaz colheita de informações sobre suspeitos de práticas ilícitas. A maior eficácia desta ferramenta significa também a possibilidade de uma maior intromissão e restrição de garantias processuais e constitucionais e de direitos fundamentais do indivíduo vigiado, o que torna o software de espionagem um método oculto de investigação de significante potencial lesivo. É em razão disso que diferentes Estados europeus vêm implementando esta novidade tecnológica em seu ordenamento jurídico com especial cautela, empregando uma racionalidade legislativa constitucionalmente orientada a fim de impedir abusos na aplicação desta gravosa ferramenta investigativa, o que infelizmente não ocorreu na legislação portuguesa. Entendemos que o legislador português tentou implementar este recurso na ordem jurídica nacional no artigo $19 .{ }^{\circ}, \mathrm{n} .{ }^{\circ}$ 2, da Lei do Cibercrime, porém não o fez da maneira adequada, com qualidade, não havendo base legal que autorize o uso de software de espionagem para fins de prevenção ou investigação em Portugal.

A atividade preventiva e investigativa do Estado necessita de acompanhar o desenvolvimento tecnológico e social, porém essa evolução deve ser sempre promovida em confor- 
midade com as orientações constitucionais, de modo a assegurar a proteção dos direitos fundamentais e das liberdades individuais.

\section{BIBLIOGRAFIA}

ANDRADE, José Carlos Vieira de - Os Direitos Fundamentais na Constituição Portuguesa de 1976. 5. ${ }^{\mathrm{a}}$ ed. Coimbra: Almedina, 2012.

ANDRADE, Manuel da Costa - Sobre as proibições de prova em processo penal. 1. ${ }^{\mathrm{a}}$ ed. (reimpr.). Coimbra: Coimbra Editora, 2013.

ANDRADE, Manuel da Costa - "Bruscamente no Verão passado", a reforma do código de processo penal: observações críticas sobre uma lei que podia e devia ter sido diferente. Coimbra: Coimbra Editora, 2009.

BOLDT, Martin - Privacy-Invasive Software - Exploring Effects and Countermeasure, 2007.138 f. Monografia de Licenciatura (Licenciatura em Ciência e Tecnologia da Computação)-Department of Systems and Software Engineering da Blekinge Institute of Technology, Karlskrona, 2007. [Consultado em: 23 de abril de 2018]. Disponível em: https://www.diva-portal.org/smash/get/diva2:837092/FULLTEXTo1.pdf.

CAIRES, João Gouveia de - O registo de som e imagem e as escutas ambientais. In Direito da Investigação Criminal e da Prova. Coimbra: Almedina, 2014, P. 273-298.

CLOUGH, Jonathan - Principles of Cybercrime. Cambridge: Cambridge University Press, 2010.

COLOMER, Juan-Luis Gómez - El processo penal español a comienzos del siglo XXI. Diagnóstico sobre sus principales problemas y propuesta de posibles soluciones, al hilo de la lucha contra la criminalidad organizada y la persecución de los delitos de corrupción. In InDret. Barcelona. ISSN 1698-739X. N. ${ }^{\circ}$ 1, 2017, p. 1-59.

CONLAN, Kevin; BAGGILI, Ibrahim; BREITINGER, Frank - Anti-forensics: Furthering digital forensic science through a new extended, granular taxonomy. In Digital Investigation. Amsterdam, New York. ISSN 1742-2876. v. 18 (Supplement), 2016, p. 566-575.

FELICIONI, Paola - Lacquisizione da remoto di dati digitali nel procedimento penale: evoluzione giurisprudenziale e prospettive di riforma. Processo Penale e Giustizia. Torino. ISSN 2039-4527. N. ${ }^{\circ}$, 2016, p. 118-138.

FÈVRE, Paul Le - Il regime della captazzione dei dati informatici nel diritto francese. In Parola alla Difesa. Pisa. ISSN 2531-680X. N. ${ }^{\circ} 1,2016$, p. 181-183.

FILIOL, Eric - Computer viruses: from theory to application. Paris: Springer, 2005.

FILIPPI, L. - L'ispe-perqui-intercettazione "itinerante": le Sezioni Unite azzeccano la diagnosi, ma sbagliano la terapia. Parola alla Difesa. Pisa. ISSN 2531-680X. N. ${ }^{\circ} 1,2016$, p. 179-181.

FORGÓ, Nikolaus; HAWELLEK, Christian; KNOKE, Friederike; STOKLAS, Jonathan - The Collection of Electronic Evidence in Germany: A Spotlight on Recent Legal Developments and Court Rulings. In: New Technology, Big Data and the Law. Singapore: Springer Nature, 2017, p. 251-279.

GERCKE, Marco - Understanding Cybercrime: A Guide for Developing Countries. Geneva: International Telecommunication Union, 2011.

GUERRIER, Claudine - Révision du code de procédure pénale 2016: le nouveau régime des interceptions électroniques. [Consultado em: 02 de Outubro de 2018]. Disponível em: http://www.juriscom.net/ wp-content/uploads/2016/10/20161026penalcomm.pdf.

HUYGHE, François-Bernard - Les Écoutes Téléphoniques. Paris: Presses Universitaires de France, 2009.

MARSHALL, Angus - Digital Forensics - Digital Evidence in Criminal Investigation. Chichester: WileyBlackwell, 2008. 
MENDES, Paulo de Sousa - Lições de Direito Processual Penal. Coimbra: Almedina, 2015.

MENDES, Paulo de Sousa - O efeito-à-distância das proibições de prova. In Revista do Ministério Público do RS. Porto Alegre. [ISSN]. N. ${ }^{\circ} 74,2013$, p. 219-228.

MIRANDA, Jorge - Direitos Fundamentais. Coimbra: Almedina, 2017.

NUNES, Duarte Alberto Rodrigues - Os Meios de Obtenção de Prova Previstos na Lei do Cibercrime. Coimbra: Gestlegal, 2018.

POOL, R. L. D.; CUSTERS, B. H. M - The Police Hack Back: Legitimacy, Necessity and Privacy Implications of The Next Step in Fighting Cybercrime. In European Journal of Crime, Criminal Law and Criminal Justice. Leiden. ISSN 0928-9569. V. 25, N. ${ }^{\circ}$ 2, 2017, p. 123-144.

PRADIILLO, Juan Carlos Ortiz - La investigación del delito en la era digital: Los derechos fundamentales frente a las nuevas medidas tecnológicas de investigación - Estudios de Progreso - Fundación Alternativas. Madrid: Fundación Alternativas, 2013.

RAMALHO, David Silva - Métodos Ocultos de Investigação Criminal em Ambiente Digital. Coimbra: Almedina, 2017.

RAMALHO, David Silva - O uso de malware como meio de obtenção de prova em processo penal. Revista de Concorrência e Regulação. Lisboa. ISSN 1647-5801. A. IV, N. ${ }^{\circ}$ 16, 2013, p. 195-243.

RODRIGUES, Benjamim Silva - Da Prova Penal - Tomo II - Bruscamente... A(s) face(s) oculta(s) dos métodos ocultos de investigação criminal. Cascais: Rei dos Livros, 2010.

VALENTE, Manuel Monteiro Guedes - O Reforço dos Princípios Constitucionais na Obtenção de Prova no Mundo Digital. Corpus Delicti - Revista de Direito de Polícia Judiciária. Brasília. ISSN 2526-4265. V. 2, N. ${ }^{\circ} 3,2018$, p. 11-25.

VALENTE, Manuel Monteiro Guedes - Processo penal - Tomo I. 3. ${ }^{\text {a }}$ ed., ver., actual. e aument. Coimbra: Edições Almedina, 2010.

VELANI, Luigi Gino - Trojan horse, strumenti investigativi e diritti fondamentali: alla ricerca di un difficile equilibrio. Parola alla Difesa. Pisa. ISSN 2531-680X. N. ${ }^{\circ} 1,2016$, p. 173-179.

VERVAELE, J. A. E. - Surveillance and Criminal Investigation: Blurring of Thresholds and Boundaries in the Criminal Justice System? In: Reloading Data Protection: Multidisciplinary Insights and Contemporary Challenges. Dordrecht, Heidelberg, London, New York: Springer, 2014, p. 115-128. 